\title{
A LEITURA EM VOZ ALTA E SUA CONTRIBUIÇÃO PARA O ENSINO: UM ESTUDO BIBLIOGRÁFICO
}

\author{
READ-ALOUD AND ITS CONTRIBUTION TO \\ TEACHING: A BIBLIOGRAPHIC STUDY
}

Marcos Suel dos Santos*

Resumo: Este artigo propõe verificar como a leitura em voz alta constitui-se uma prática necessária ao ensino e à aprendizagem, em diferentes práticas discursivas nas aulas de Língua Portuguesa. Para isso, recorre-se a um estudo teórico, de base bibliográfica, sedimentado na pesquisa qualitativa, para evidenciar como a prática da leitura em voz alta pode tornar-se uma aliada ao professor, não somente para sinalizar pontos que precisam melhorar, mas para contribuir com o desenvolvimento de habilidades específicas à leitura, compreensão e, por extensão, à oralidade e à produção de textos. Como resultado, percebeu-se que a prática da leitura em voz alta na sala de aula é uma atividade necessária e sua contribuição extremamente importante para a leitura e compreensão, oralidade, produção e revisão textual, além de servir como sinalizadora para detectar problemas relacionados à decodificação, à fluência da leitura e à compreensão.

Palavras-chave: aprendizagem e ensino; leitura em voz alta; prática.

ABstract: This article aims to verify how read-aloud is a necessary practice for teaching and learning in different discursive practices in Portuguese language classes. For this, a theoretical study based on bibliography, based on qualitative research, is used to present how the practice of read-aloud can become an ally to the teacher, not only to point out points that need improvement, but to contribute to the development of specific skills in reading, comprehension and, by extension, orality and text production. As a result, it was realized that the practice of read-aloud in the classroom is a necessary activity and its extremely important contribution to reading and comprehension, orality, production and textual revision, in addition to serving as a signal to detect problems related to decoding, reading fluency and comprehension.

KEYworDs: learning and teaching; read-aloud; practice.

\footnotetext{
"Doutorando em Linguística pela Universidade Federal de Alagoas. Mestre em Letras pela Universidade Federal de Alagoas. Especialista em Letras: português-inglês pela Faculdade São Luís de França. Especialista em Neuroaprendizagem pela Universidade Norte do Paraná. Graduado em Letras pela Universidade Norte do Paraná. E-mail: markus-christie@ uol.com.br.
} 


\section{CoNSIDERAÇõES INICIAIS}

Em sua trajetória milenar, a leitura em voz alta sempre esteve presente como prática de leitura necessária e essencial em diferentes contextos, como o histórico, cultural, social, convivial, religioso, escolar, etc. Isso pressupõe entender que a leitura em voz alta surgiu com a gênese da leitura em si, quando os primeiros leitores - também os primeiros escribas inscreviam em tabuletas de argila os primeiros sinais gráficos, o que mais tarde viriam a ser chamados de "os primeiros textos" e "as primeiras leituras", consequentemente. É claro que, ao longo dos anos, escrita e leitura evoluíram. Nesse cenário, a história da leitura em voz alta está associada a leituras públicas a senhores abastados ou à população pobre e analfabeta e tinha, portanto, caráter público, convivial e social.

Com o processo evolutivo dos suportes de leitura, a leitura em voz alta foi até certo ponto uma prática soberana, pois a ela competia toda a forma de leitura, uma vez que a leitura silenciosa era uma prática realizada por poucas pessoas, dentre elas os monges, como Santo Ambrósio, pessoa totalmente instruída. A leitura em voz alta era realizada por um leitor que fazia a leitura como um trabalho aos seus senhores ou como trabalho recompensado (pagamento) por aqueles que não sabiam ler, os analfabetos. Porém, foi com a invenção da imprensa que a leitura em voz alta começou a declinar, ou seja, a perder o posto de prática soberana para a leitura silenciosa. É claro que essa revolução é justificável, pois com a publicação de mais livros, mais pessoas tornavam-se leitores e liam os textos sem pressa, ascendendo, aos poucos, à leitura silenciosa como prática soberana.

Em termos de ensino, sobretudo no século XX, a leitura em voz alta foi negligenciada sob várias acusações, como uma prática cansativa e repetitiva aos alunos, uma atividade de leitura que não possibilitava a compreensão de textos, além de ser uma prática constrangedora, porque "para os alunos com dificuldades, ler diante dos outros era, às vezes, um suplício [...]" (CHARTIER, 2011, p. 180). Em virtude disso, talvez, documentos oficiais criados pelo Ministério da Educação (PCN, 1997; BNCC, 2017) mencionem eventualmente a leitura em voz alta como uma prática pouco utilizada no ensino. No entanto, estudos realizados por pesquisadores nacionais e internacionais (LANDIM; FLÔRES, 2019; OLIVEIRA; ARAÚJO, 2019; MIRANDA, 2015; POERSCH; MUNEROLI, 1993) evidenciam a grande contribuição desse tipo de leitura para o desenvolvimento de habilidades referentes à leitura, compreensão, oralidade e produção de textos.

Nessa perspectiva, este texto se propõe a analisar textos acadêmicos e verificar a contribuição da leitura em voz alta para o ensino e a aprendizagem de Língua Portuguesa, a partir de diferentes perspectivas de ensino. Para isso, foram analisados 5 textos, sendo 3 artigos científicos publicados em periódicos (revistas) e 2 dissertações publicadas nos repositórios das instituições de origem. Para nortear o estudo, partimos do seguinte questionamento: em que medida a leitura em voz alta pode constituir-se como um elemento necessário ao ensino 
e à aprendizagem da leitura em sala de aula nos dias atuais? Assim, recorremos à pesquisa bibliográfica, de cunho qualitativo para responder a essa pergunta e perceber como se dá esse processo nos textos analisados.

O viés teórico que embasa este estudo constitui-se, sobretudo, pelas teorias de leitura e da leitura em voz alta em seus aspectos sociais, culturais, conviviais e escolares. Encontramos em Jean (1997) e Manguel (1997) os pressupostos para a história da leitura e da leitura em voz alta. Situamo-nos nos estudos de Horellou-Lafarge e Segré (2010), para entender a leitura em voz alta numa abordagem social. Em Chartier (1994), para compreendermos a leitura a partir da revolução da leitura como prática extensiva e intensiva; além dos trabalhos de Oliveira e Araújo (2019), Landim e Flôres (2019), Poersch e Muneroli (1993), Miranda (2015) e Santos (2016).

\section{ACERCa da LEITURA EM VOZ ALTA E SUA HISTÓRIA}

Para entendermos a importância da leitura em voz alta na conjuntura histórica da leitura e consequentemente sua contribuição para a formação de sociedades leitoras e letradas em diferentes contextos históricos, partimos do fato de que "as palavras escritas, desde os tempos das primeiras tabuletas sumérias, destinavam-se a ser pronunciadas em voz alta, uma vez que os signos traziam implícito, como se fosse sua alma, um som particular" (MANGUEL, 1997, p. 61).

Assim, compreendemos que toda leitura praticada pelos primeiros leitores - os escribas - era em voz alta, estendendo-se por vários séculos até chegar à leitura silenciosa em sua forma mais extensiva, por volta do século XVI, com a invenção da imprensa. Isso não quer dizer que essa prática de leitura não existia nos séculos anteriores; pelo contrário, a leitura silenciosa existe desde a Antiguidade e era realizada por pouquíssimas pessoas. Infere-se, de Santo Agostinho (2017), que liam silenciosamente aqueles que eram dotados de grande inteligência e sapiência. Um dos primeiros registros dessa leitura, no Ocidente, data do final do século IV e é relatado por Santo Agostinho quando, maravilhado com a proeza que viu, deparou-se com Santo Ambrósio lendo. Santo Agostinho (2017, p. 146) relata que "lendo, os olhos percorriam as páginas e o coração penetrava o sentido; a voz e a língua, porém, permaneciam em repouso". Segundo Manguel (1997), apesar desse e de outros possíveis registros de leitura silenciosa, é somente no século $\mathrm{X}$ que essa leitura se torna usual no Ocidente.

Fischer (2006) afirma que as leituras entre os babilônicos eram transcrições fiéis dos textos impressos em tabuletas; portanto, sem haver interferência do escriba-leitor. Estes escreviam e liam os textos conforme lhes eram ditados por seus superiores ou senhores iletrados, de modo que a leitura realizada em voz alta por esses leitores ou faziam parte de suas tarefas usuais ou uma pequena taxa era cobrada dos ouvintes. Ainda segundo o autor, além desses ouvintes superiores, a leitura em voz alta destinava-se também às camadas sociais 
inferiores, como os analfabetos, que se reuniam em locais públicos para ouvirem os leitores lerem os poucos textos que havia.

Diante disso, percebe-se que a leitura em voz alta desempenhava diferentes funções, como o caráter privativo ou público, social e convivial; além de servir tanto aos superiores e abastados como aos inferiores e desabastados. Uma outra função era a transmissão de informações, histórias ou a recitação de textos poéticos em lugares públicos. A leitura vista como uma mercadoria/atividade, na qual, em alguns contextos para ser ouvida, os ouvintes deveriam pagar aos leitores. Ou seja, era uma prática monopolizada.

Sendo assim, ainda na Antiguidade, entre os latinos, a leitura em voz alta também era praticada em lugares públicos, sem monopólios, até a queda do Império Romano. Após esse período, na Idade Média, a igreja passou a monopolizar a cultura e a produção de livros religiosos, entre os séculos V e XII. Segundo Horellou-Lafarge e Segré (2010, p. 26), "a leitura, feita em voz alta, se praticava somente nas igrejas, nos refeitórios e nos claustros e abrangia apenas os textos sagrados em latim”.

Convém destacar que, até o século IX, a leitura era uma atividade difícil, porque as letras e as palavras estavam unidas umas às outras. Não havia pontuação, nem inserção de letras maiúsculas no texto escrito, vindo a se fazer presentes progressivamente tempos depois. A segmentação das palavras surgiu com os monges copistas, que orientavam o leitor a regular a intensidade da voz (baixa ou alta) ao final de um pensamento. Segundo Jean (1997, p. 35-36), "os gregos [...] escreviam em scriptio continua, ou seja, sem intervalo entre as palavras, o que -a experiência mostra-o - torna a leitura em voz alta praticamente necessária”.

Nesse período, a igreja detinha o poder de instrução da leitura, e o ensino era destinado somente aos meninos, excluindo as meninas desse processo sob justificativa de que elas deveriam aprender os ofícios do lar, o que já confirma e sustenta a leitura como uma prática machista, no contexto histórico-social da época. Caso elas decidissem ser freiras, o ensino da leitura era-lhes permitido.

Após o século XII, o ensino da leitura continuou sendo validado pela igreja, já que outras instituições, como as "escolas de caridade", passaram a ensinar as crianças (filhos da elite), possibilitando o acesso à leitura. Mas, foi somente no final do século XVIII que "a instrução tornou-se um assunto do Estado e não mais um dever da Igreja. [...] o Estado era responsável em matéria de educação" (HORELLOU-LAFARGE; SEGRÉ, 2010, p. 48).

Diante dessas considerações, percebe-se claramente o papel social da leitura, enquanto prática oral. Toda leitura em voz alta realizada manifestava interesses sociais em comunicar, transmitir alguma informação para alguém ou para grupos de pessoas, que, por sua vez, torna-se também um exercício de convivialidade entre leitor e ouvinte numa complexa rede de conexões entre o dito, expressado e a compreensão que se faz da leitura ouvida. Deve-se observar que a leitura em voz alta, quando ocorre num encontro individual, exclui a função convivial da leitura. 
No todo, a leitura em voz alta era uma leitura 'recebida' por um grupo de monges, de estudantes, de colegiais e, mais tarde, de gentes do povo a quem, tanto na cidade como no campo, eram lidas páginas dos almanaques ou dos célebres livrinhos da Biblioteca azul de Troyes (JEAN, 1997, p. 60).

Nesse sentido, a convivência da leitura em voz alta entre distintos grupos sociais só fazia sentido se leitores e ouvintes discutissem o que liam, tornando essa prática momentos ativos de leitura, diferentemente daqueles realizados nos mosteiros onde os monges, por razões religiosas, não discutiam a Palavra de Deus, visto que não se autorizava qualquer que fosse explicação pessoal da Bíblia, sendo essa responsabilidade do poder eclesiástico.

Portanto, sendo a leitura em voz alta uma atividade para os outros, essa prática leitora "assume cada vez mais uma função social" (JEAN, 1997, p. 61), pois é por meio dela que leitor e ouvinte estão ligados pela voz, numa relação de intimidade e de cumplicidade, uma vez que um empresta sua voz carregada de informações para o outro, que se propõe a produzir os sentidos oriundos da pronúncia das palavras. Daí, pode-se pensar na seguinte situação de leitura: um telespectador que assiste a um telejornal acredita nas informações que são transmitidas pelo âncora que apresenta esse telejornal, por veicular sempre notícias confiáveis. O âncora lê os textos pelo teleprompter de modo tão expressivo e eloquente que o telespectador, às vezes, nem se dá conta de que está ouvindo textos sendo lidos em voz alta. Essa relação estabelecida pela confiança do ouvinte situa-se nas dimensões de intimidade, convivialidade e sociabilidade.

Na primeira metade do século XVIII, a leitura em voz alta é considerada por excelência uma prática de leitura intensiva, isto é, leituras intensas realizadas por meio de textos que eram lidos e relidos inúmeras vezes, cujo leitor é "confrontado com um corpus limitado e fechado de textos lidos e relidos, memorizados e recitados, ouvidos e sabidos de cor, transmitidos de geração a geração" (CHARTIER, 1994, p. 189). Isso porque, apesar de a leitura silenciosa já ter se instaurado como prática de leitura extensiva, a leitura em voz alta ainda permanecia soberana, não como antes, nas sociedades letradas, nas instituições de ensino e principalmente nas celebrações religiosas.

Outro aspecto dessa prática de leitura intensiva é o fato de os leitores lerem poucos e sempre os mesmos textos, já que a produção e a circulação de livros não eram acessíveis a todas camadas sociais. Inclusive os suportes textuais não possibilitavam a leitura de vários textos. Em todo caso, a leitura em voz alta é uma atividade bastante lenta e cansativa, se comparada à leitura silenciosa, uma vez que o leitor não pode voltar ao texto no ato da leitura, pois o seu ouvinte ou público perceberá o ato e pode julgá-lo como alguém que não domina o texto.

Segundo Chartier (1994), a leitura passou por duas importantes revoluções. A primeira foi a transformação da prática oral da leitura na prática silenciosa da leitura. A segunda refere--se aos estilos intensivos e extensivos da leitura. Embora a leitura em voz alta tenha prevalecido soberana durante vários séculos, desde a Antiguidade até a Idade Moderna, mais 
especificamente na Europa, o pesquisador francês diz que não se pode afirmar que a leitura silenciosa não existia na Antiguidade, visto ser a leitura em voz alta uma prática que atendia a uma convenção cultural que fortemente associava o texto à voz e à leitura.

Mas foi a partir dessa revolução que a leitura em voz alta passou a declinar entre as sociedades ocidentais em diferentes períodos, deixando de ser uma atividade sujeita ao controle de outrem para se tornar uma atividade extensiva, mais rápida, cujo acesso aos materiais escritos foi condição necessária para leituras silenciosas. Assim, "as conquistas da leitura silenciosa não podem, portanto, ser separadas da mutação maior que transforma a própria função da escrita" (CHARTIER, 1994, 188).

Em face disso, a leitura em voz alta não pode ser considerada uma prática de leitura marginalizada - embora ainda seja -, visto sua contribuição para a formação leitora de diversas e distintas sociedades que, aos poucos, incorporaram diferentes funções à leitura. Sem dúvida, o status perdido da leitura em voz alta nas sociedades atuais ocorreu conforme a necessidade dos leitores, das condições de produção dos textos e dos suportes em que são escritos. Apesar de a leitura silenciosa ser a prática hegemônica de leitura atual, a leitura em voz alta ainda continua, bem menos, exercendo diferentes funções: social, convivial, reparadora e pedagógica.

O ensino da leitura e da escrita surge de maneira rudimentar em decorrência da alfabetização de jovens, que mais tarde viriam a se tornar escribas profissionais, conforme afirma Fischer (2006, p. 20): "para se tornar um escriba profissional na Babilônia, em 1700 a.C., os garotos tinham de frequentar, dos seis aos 18 anos, a escola de formação de escribas, desde o início do período matutino até o final do vespertino durante 24 dias de cada trinta”. Nesse período, aprender a ler consistia na reescrita de textos, pois:

[...] a leitura era aprendida pelo ato de escrever. Primeiro, o professor cobria um lado de uma pequena tabuleta com um sinal, depois o aluno escrevia o mesmo sinal repetidas vezes no verso. Em seguida, dois sinais eram colocados juntos para formar uma palavra inteira, reproduzida de maneira similar pelo aluno (FISCHER, 2006, p. 21).

A repetição mecânica do ato de virar a tabuleta forçava o aluno a tornar-se um leitor e escritor independente, uma vez que ele recorria à memorização, por meio da visualização para reescrever os sinais. Esse método de ensino da leitura denominado "palavra inteira" consistia em o aluno ter de memorizar não só os sinais simples, mas palavras, nomes e frases inteiras (FISCHER, 2006).

Mais adiante, modelos similares de escola foram sendo criados entre outras sociedades, como a egípcia, a grega e a romana, com os mesmos objetivos, mas em condições mais sofisticadas, conforme os modelos de escrita iam evoluindo em face da invenção do alfabeto. De acordo com Jean (1997, p. 56), "desde a Idade Média europeia, o ensino era ministrado ainda oralmente a alguns privilegiados, e com maior frequência através de leituras em voz alta literalmente ritualizadas". 


\section{A leitura em voz alta em documentos oficiais}

Estudiosos, como Morais (2013), destacam a importância de se ler para as crianças que estão no processo de alfabetização, de aprendizagem da leitura. $O$ autor defende a leitura partilhada como uma prática necessária e essencial para o desenvolvimento leitor das crianças, pois argumenta em favor de que "a leitura partilhada permite à criança adquirir conhecimentos que serão importantes para a aprendizagem da leitura" (MORAIS, 2013, p. 3). Essa denominação de leitura requer a presença de um leitor e este faz a leitura em voz alta para que a criança ouça e daí possa interagir com o texto, a história. Nesse sentido, a leitura partilhada é um modo de ler o texto em voz alta para um determinado público ouvinte.

Na dimensão do ensino e sob a perspectiva de alguns documentos oficiais (PCN, 1997; BNCC, 2017), conclui-se que a leitura em voz alta ainda não é valorizada, tampouco bem quista no ensino da leitura. Isto não quer dizer que ela não está presente nas salas de aulas. Está, mas como uma prática bastante secundária, sendo utilizada, principalmente, nos primeiros anos do ensino fundamental, com a função, quase sempre, avaliadora, ou seja, ela é quem diz se a criança já lê e como é essa leitura. Nos anos finais do ensino fundamental e no ensino médio, a leitura em voz alta é praticamente negligenciada, atendendo a apenas alguns propósitos como leitura de poemas, teatralização, ou textos orais que, de fato, exigem a voz para serem comunicados de modo expressivo.

A Política Nacional de Alfabetização (PNA), instituída em 2019 e considerada um marco na educação brasileira, menciona a leitura em voz alta apenas três vezes. Na primeira, como elemento essencial para o desenvolvimento das habilidades referentes à literacia da criança (educação infantil), após haver o envolvimento dos pais, isto é, estes leem para seus filhos, o que sustenta a teoria de Morais (2013). A segunda pressupõe que:

uma das práticas que têm maior impacto no futuro escolar da criança é a leitura partilhada de histórias, ou leitura em voz alta feita pelo adulto para a criança; essa prática amplia o vocabulário, desenvolve a compreensão da linguagem oral, introduz padrões morfossintáticos, desperta a imaginação, incute o gosto pela leitura e estreita o vínculo familiar (BRASIL, 2019, p. 23).

É importante ressaltar a leitura partilhada realizada por um adulto para a criança, o que implica dizer que esse adulto não é o professor, porque o documento é enfático quando cita a literacia familiar, ou seja, esse adulto (pai, mãe, irmãos, etc.) promove a leitura como uma forma de convivialidade familiar, e não uma leitura realizada pelo professor na escola. Corroboramos com a citação acima, pois a leitura partilhada em voz alta abre um leque de possibilidades de aprendizagem, além de promover o gosto pela leitura. Porém compete ao professor realizar essa atividade também na escola. 
A terceira vez em que aparece enfatiza a importância da leitura em voz alta como uma atividade desenvolvedora indireta do vocabulário. O documento destaca ainda o termo leitura oral sempre associado ao termo fluência, ou seja, quando a criança é capaz de ler com precisão, velocidade e prosódia: "A fluência torna a leitura menos trabalhosa e mais agradável. É desenvolvida em sala de aula pelo incentivo à prática da leitura de textos em voz alta, individual e coletivamente, acrescida da modelagem da leitura fluente" (BRASIL, 2019, p. 33).

Nessa modelagem da leitura fluente, reside implicitamente a figura do professor como modelo de leitor fluente. Nesse caso, observa-se a leitura em voz alta como um elemento de caráter avaliativo, já que "o monitoramento do progresso dos alunos na fluência permite ao professor conhecer com mais detalhes os problemas de leitura de cada um e, assim, oferecer-lhe a ajuda necessária" (BRASIL, 2019, p. 33).

Em 1997, os Parâmetros Nacionais Curriculares (PCN) de Língua Portuguesa admitem a leitura em voz alta como uma prática tradicional, secundária e negligenciada nas salas de aula, uma vez que, em muitos casos, está sempre associada à uma leitura com finalidades avaliativas ou constrangedoras aos estudantes, pois, quando são promovidas, são fragmentadas, sem sentido, sem o redirecionamento de práticas leitoras que garantam reflexões acerca da relação uso-reflexão-uso. Assim, estes documentos assinalam que esta prática de leitura seja utilizada em atividades de leitura permanente, de modo que "os alunos escolhem o que desejam ler, levam o material para casa por um tempo e se revezam para fazer a leitura em voz alta, na classe" (BRASIL, 1997, p. 46). Nessa situação didática, dois aspectos são destacados: a autonomia na escolha dos textos e a leitura fragmentada.

No primeiro aspecto, percebe-se claramente a imposição da leitura silenciosa como antecedente à leitura em voz alta, pois "o aluno deve sempre poder ler o texto silenciosamente, com antecedência - uma ou várias vezes" (BRASIL, 1997, p. 45). Entretanto, o documento deixa claro que esse tipo de atividade sempre deve fazer sentido para o aluno e para a turma. O segundo aspecto, considerando o revezamento da leitura em voz alta, pode tornar-se uma atividade mecânica e exaustiva, se não for metodologicamente direcionada. Na maioria das vezes, a fragmentação do texto é um pretexto para que todos os estudantes da sala leiam o texto em voz alta.

Além disso, "a leitura em voz alta feita pelo professor não é prática comum na escola. $\mathrm{E}$, quanto mais avançam as séries mais incomum se torna, o que não deveria acontecer, pois, muitas vezes, são os alunos maiores que mais precisam de bons modelos de leitores" (BRASIL, 1997, p. 73). Sem dúvida, o estudante torna-se um leitor fluente quando é inserido em contextos leitores promovidos por outros agentes, no caso da escola, o professor. Este, por sua vez, trabalha a leitura em voz alta de forma limitada, isto é, muitas vezes com finalidades avaliativas (decodificação, pontuação, entonação, etc.). Em outros casos, a leitura realizada pelo professor não faz sentido quando é realizada sem provocações, sem estímulos aos alunos. 
Nos anos iniciais do ensino fundamental, uma vez que se trata dos processos de alfabetização, essas leituras são mais frequentes até porque a maioria dos alunos não consegue ler, em termos de decodificação, textos curtos, como poemas, parlendas, cantigas, etc. Nos anos finais do ensino fundamental e no ensino médio, a leitura em voz alta realizada pelo professor praticamente é inexistente.

A Base Nacional Comum Curricular (BNCC) (2017), por sua vez, menciona a leitura em voz alta em duas passagens somente. Duas delas nas habilidades (EF35LPoI) - anos iniciais do ensino fundamental - e (EF69LP53) - anos finais do ensino fundamental. Na primeira habilidade, é priorizada tanto a leitura silenciosa quanto a leitura em voz alta. Em ambas leituras, o estudante deve ler e compreender textos com autonomia e fluência, utilizando-se de textos curtos e com o nível de textualidade adequado. Essa habilidade refere-se aos estudantes dos terceiros aos quintos anos. Na segunda habilidade, o foco é a leitura de textos literários diversos, cujo objetivo é verificar aspectos como ritmo, entonação, fluência, pausas, hesitações, etc. Estas habilidades não preveem o uso da leitura em voz alta como uma atividade que fomente, desperte o gosto pela leitura no estudante ou que direcionam a diferentes modos e finalidades dessa prática leitora, necessária ao ensino e à aprendizagem da leitura.

Embora somente as duas habilidades citem explicitamente a leitura em voz alta, há outras habilidades que pressupõem implicitamente o uso da leitura em voz alta. Sabemos ainda que o documento não diz qual metodologia o professor deve seguir, apenas as habilidades devem ser contempladas. Com isso, o professor tem autonomia para, a partir das habilidades, refletir quando e de que modo a leitura em voz alta pode estar presente nas aulas de Língua Portuguesa e nos demais componentes curriculares também, caso, assim, desejem os professores das outras áreas. Enfatizamos que a leitura em voz alta não é uma atividade exclusivamente do componente curricular de Língua Portuguesa, embora, neste estudo, priorizemos neste componente.

\section{Aspectos metodológicos}

Esta pesquisa tem como corpus 5 textos acadêmicos, sendo 3 artigos científicos publicados em periódicos científicos (revistas) e 2 dissertações disponíveis nos repositórios de origem. A seleção desses textos deu-se porque discutem a importância da leitura em voz alta para o ensino e a aprendizagem de Língua Portuguesa, uma vez que as discussões foram geradas a partir do microcosmo da sala de aula e contribuem para o desenvolvimento de práticas didático-pedagógicas que melhor possibilitem o trabalho do professor em diferentes práticas discursivas.

Assim, a pesquisa é de abordagem qualitativa, já que a intenção é interpretar os dados mencionados nos textos selecionados, considerando os contextos de aplicabilidade de cada pesquisa, isto é, a sala de aula. Para isso, buscou-se na pesquisa bibliográfica subsídios para as 
interpretações dos dados, pois é intenção deste texto apresentar, mesmo em número limitado de textos selecionados, a importância da leitura em voz alta advinda dos estudos acadêmicos e geradores de atividades essenciais com essa prática leitora em sala de aula.

É importante considerar, também, que pesquisas atendendo a leitura em voz alta e sua contribuição para o ensino ainda são poucas. Na verdade, há muitos textos que se utilizam da leitura em voz alta para outros fins, sobretudo, no campo da Fonoaudiologia. No que se refere aos estudos linguísticos, ainda são moderados. A Psicolinguística também se preocupa com a leitura em voz alta, mas com um viés cognitivo.

\section{REVISITANDO ALGUNS ESTUdOS}

Tecidas algumas considerações históricas da leitura em voz alta e das suas contribuições para a formação de leitores e para o desenvolvimento da leitura, apesar das muitas críticas que recebeu, pelo menos, nos séculos XVIII, XIX e XX, sobretudo, porque era uma atividade repetitiva e exaustiva para os estudantes, não assegurava a compreensão leitora, já que o processamento da leitura era lento devido a não regressão ao texto enquanto a leitura em voz alta acontecia. Nos últimos anos do século XXI, a leitura em voz alta tanto no cenário nacional como no internacional vem assumindo, a passos muito lentos, papel de relevância e destaque no ambiente pedagógico. É claro que a leitura em voz alta a que nos referimos não é aquela destinada somente à decodificação do texto escrito, mas aquela que possibilita ao leitor, ao estudante compreender o texto que lê a partir da expressividade que é dada a essa prática de leitura. É uma prática que tem como finalidade comunicar ou fazer entender o texto.

De modo a contribuir com a prática da leitura em voz alta na educação em diferentes manifestações nas aulas de Língua Portuguesa, e tendo em vista a leitura deste texto por pesquisadores e professores da Educação Básica, que de alguma maneira pensam em trabalhar a leitura em voz alta de forma ativa e reflexiva na escola, revisitamos alguns estudos recentes que discutem a importância e a contribuição significativa dessa prática de leitura no ensino e na aprendizagem da oralidade, da leitura, da escrita e da análise linguística/ortográfica em artigos pesquisados em periódicos científicos e dissertações. Ou seja, a leitura em voz alta já não assume uma função passiva em termos de ensino, se é que algum dia ela, de fato, foi passiva. Mesmo quando era praticada para verificar o nível de leitura dos alunos, desempenhava uma função pedagógica. Talvez, esse seja o grande implicador de uma prática de leitura negativa na escola.

A pesquisa de Oliveira e Araújo (2019), intitulada Leitura em voz alta e discussões orais: estratégias de ensino nas aulas de Língua Portuguesa, busca discutir os efeitos das instruções de leitura mobilizadas nas aulas de Língua Portuguesa por uma professora estagiária, visando estabelecer uma relação entre essas instruções, o engajamento dos alunos nas discussões orais 
e as dúvidas que eles demonstraram na leitura em voz alta. Concernente à leitura silenciosa, as pesquisadoras também avaliaram esse engajamento com o texto lido.

Para realizar o estudo em discussão, as autoras valeram-se de dois tipos de pesquisa: qualitativa e documental, além da análise de conteúdo. Por meio da pesquisa qualitativa, elas descreveram e analisaram o modo como a professora estagiária acionava as instruções durante as aulas ministradas. A documental serviu para as análises das anotações da professora, como meio de descrever os registros das aulas. Nas análises de conteúdo, elas encontraram as respostas para suas questões acerca do tema pesquisado, considerando três fases: pré-análise, exploração do material e tratamento dos dados e interpretação. Para tanto, a pesquisa foi realizada em uma escola estadual de ensino fundamental e médio, de um município de Belém (PA), tendo como participantes a professora estagiária (estudante de Letras) e 35 alunos, com idade em média de 15 anos, do $9^{\circ}$ ano do Ensino Fundamental.

Segundo as autoras (OLIVEIRA; ARAUJO, 2019, p. 774), "a estagiária utilizou diferentes modos de instrução, como: leitura em voz alta, leitura silenciosa e discussão oral sobre o texto". Diante dessa constatação, elas relacionaram "essas formas de ensinar ao engajamento dos alunos nas atividades e à quantidade de questionamentos que fizeram ao longo de cada etapa da sequência didática" (OLIVEIRA; ARAUJO, 2019, p. 774).

À propósito da leitura em voz alta, Oliveira e Araújo (2019) concluíram que esse modo de instrução possibilitou menos questionamentos ou dúvidas dos alunos em relação às atividades propostas, o que supostamente contribuiu para a compreensão dos textos lidos em voz alta. Outro ponto forte dessa instrução é um maior engajamento dos alunos, pois, segundo as pesquisadoras, "nas aulas em que a leitura em voz alta não ocorreu com tanta frequência, o engajamento dos alunos foi menor" (OLIVEIRA; ARAUJO, 2019, p. 776). Assim, compreende-se que uma das funções da leitura em voz alta é a motivação dos alunos para a construção de conhecimentos do texto. Por outro lado, a leitura silenciosa mostrou-se menos eficiente em termos de engajamento e compreensão, uma vez que "os dados revelaram que, quando os alunos precisavam ler sozinhos, mostraram bastante dificuldades no que diz respeito à compreensão dos textos e dos comandos das atividades, o que talvez indique problemas de leitura" (OLIVEIRA; ARAÚJO, 2019, p. 776).

No que se refere às discussões orais sobre os textos, as autoras verificaram "que, nas aulas analisadas, a leitura em voz alta seguida de discussão parece ter contribuído para o posicionamento crítico dos alunos diante do texto, uma vez que propuseram finais diferentes para o conto 'A tenebrosa noite de tempestade', lido oralmente pela estagiária” (OLIVEIRA; ARAÚJO, 2019, p. 779).

No relato de pesquisa Leitura oral: uma variável facilitadora de compreensão, as pesquisadoras Landim e Flôres (2019) consideram leitura e compreensão como duas atividades cognitivas distintas, amparadas pelos estudos da Neurociência, partindo do pressuposto que ler é decodificar, em sentido estrito, e decodificar não implica compreender. Elas ponderam 
que os problemas de leitura revelados a partir dos resultados de avaliações externas como as Prova Brasil/SAEB, ANA e PISA refletem interesses de que a leitura em voz alta associada à compreensão voltasse a ser investigada. Com base nessas reflexões, as autoras se propuseram a investigar, por meio de um estudo exploratório, as possíveis dificuldades evidenciadas por um grupo de acadêmicos de Letras, de uma IES, do RS. Além disso, analisaram a possibilidade de esses alunos apresentarem distúrbios cerebrais ou se apresentavam falta de prática leitora, para fins acadêmicos. Nesse caso, os estudantes foram expostos a diferentes atividades, como: leitura silenciosa, produção de paráfrase, leitura em voz alta e gravação de leitura, de modo que os participantes deveriam monitorar o desempenho do grupo a partir dos seguintes critérios: diç̧ão, ritmo e entonação.

Nesse sentido, participaram da pesquisa 13 estudantes do curso de Letras, no primeiro semestre de 2016. Inicialmente, os estudantes tiveram de ler silenciosamente uma crônica e em seguida produziram uma paráfrase. Na segunda aula, eles leram em voz alta a paráfrase; nesse caso, as leituras foram gravadas para análises posteriores. As pesquisadoras utilizaram três critérios, a saber: dicção, ritmo e entonação. O ponto mais relevante da pesquisa consiste nas análises coletivas do material gravado, isto é, a professora e os estudantes da turma fizeram juntos as análises, de modo a permitir maior observação em relação aos desvios observados em cada critério estabelecido.

De acordo com as autoras, "a junção das duas fontes de observação concluiu que nenhuma das leituras foi impecável, perfeita, pois todos os leitores cometeram algum deslize relacionado, sobretudo, ao ritmo" (LANDIM; FLÔRES, 2019, p. 32). Nesse critério, ocorreram situações, tais como: correções de palavras já lidas, precipitação na leitura, lentidão exagerada da leitura, pausas inadequadas, troca de acento de palavras. "As demais leituras foram consideradas boas, pois não apresentaram muitos deslizes (no máximo quatro), ainda que não tivessem sido suficientemente expressivas" (LANDIM; FLÔRES, 2019, p. 33). Em termos de dicção, apenas uma falha (pronúncia de uma frase interrogativa como declarativa) é vista pelas autoras como um fator de desatenção do leitor, de modo que a leitura possa ter-lhe surgido com alguma dificuldade de compreensão. Em conclusão a esse critério, as autoras perceberam que mais pesquisas sobre a dicção são necessárias, de modo a verificar se a dicção é, de fato, um fator fraco referente ao indicador da compreensão. A entonação relaciona-se à decodificação e vinculação à compreensão, pois, "além disso, foi praticamente inviável separar os fatores entonação, intensidade e duração, já que não se dispunha de instrumentos de análise precisos (LANDIM; FLÔRES, 2019, p. 33).

De modo geral, as autoras sumarizam que: a) algumas atitudes são necessárias ao desenvolvimento pelo gosto da leitura e consequentemente da habilidades e competências da compreensão leitora, assim como uma revisão na postura do professor em relação à sua metodologia de trabalho em sala de aula; b) "é preciso investir em pesquisas sobre o ensino da leitura" e que os resultados da pesquisa "autorizam que se sugira aos professores ler em voz 
alta para seus alunos e vice-versa"; c) é significativo "retomar as práticas de leitura oral, sem exigências avaliativas anteriores, que eram, realmente, inadequadas e intransigentes". Logo, entende-se que a leitura em voz alta "coopera para o amadurecimento do leitor, para o incremento e despertar do gosto pela leitura e, também, para o desenvolvimento da competência leitora" (LANDIM; FLÔRES, 2019, p. 34).

Assim, a leitura em voz alta desempenha funções necessárias à compreensão tanto no contexto escolar como no acadêmico, com vista enfática do que nos dizem Poersch e Muneroli (1993, p. 13) e com o assentimento de Landim e Flôres (2019), a leitura em voz alta é "uma variável facilitadora de compreensão".

Poersch e Muneroli (1993) discutem no artigo O leitor como intérprete das pistas que o escritor insere no texto: a leitura oral expressiva duas premissas acerca da leitura, sendo que a primeira se relaciona às conexões entre leitura e escritura no plano dimensional da explicação. A segunda, por sua vez, põe em evidência que o leitor, ao ler um texto em voz alta, precisa compreendê-lo em toda sua extensão e complexidade. Diante disso, os autores recorrem a evidências empíricas para, de fato, verificarem se há relação associativa entre leitura em voz alta e compreensão.

Para isso, elegeram como participantes da pesquisa 20 estudantes da $8^{a}$ série $\left(9^{\circ}\right.$ ano atualmente), de uma escola urbana, além de terem escolhido o teste cloze e a leitura em voz alta gravada como coleta de dados. Esses dados tinham como finalidade verificar a compreensão e a expressividade de leitura dos estudantes respectivamente. A expressividade foi analisada segundo três componentes: dicção, ritmo e entonação. Um aspecto a ser considerado na coleta dos dados é que o fragmento do texto expositivo lido individualmente pelos estudantes foi o mesmo utilizado no teste cloze, ou seja, eles já conheciam o texto o que, por si só, já pressupunha expressividade.

Diante disso, os autores (POERSCHI, MUNEROLI, 1993, p. 23) concluíram que "a leitura oral expressiva realmente constitui um indicador de compreensão textual”. Assim, "a dicção, embora constitua um componente da expressividade, está mais relacionada com a recodificação do que com a decodificação". Enquanto "a entonação e o ritmo se relacionam mais fortemente com a compreensão do que a dicção porque são elementos ligados à decodificação". É claro que quando o estudante decodifica satisfatoriamente um texto, as possibilidades de compreendê-lo tornam-se maiores.

Miranda (2015), na dissertação intitulada A influência da leitura em voz alta na revisão de textos de alunos do $9^{\circ}$ ano do ensino fundamental, recorreu à leitura em voz alta para verificar em que medida essa prática de leitura pode influenciar na reescrita de textos, de modo a torná-los conscientes em suas produções escritas futuras. A partir desse interesse de pesquisa, a autora elabora algumas questões que pretende responder durante a pesquisa. Contudo, interessa-nos, para fins de reflexão, as seguintes perguntas: a) pode a leitura oral ser um instrumento na reescrita de um texto?; b) qual o papel da leitura oral na revisão (e posterior reescrita) de um texto produzido pelo aluno, quando ele assume o papel de produtor (autor) e leitor do texto? 
Metodologicamente, a pesquisa contou com 27 estudantes do $9^{\circ}$ ano do ensino fundamental de uma escola pública de Belo Horizonte. Após lerem e ouvirem causos, gênero elegido, "passou-se à produção individual de um causo; no próximo passo solicitou-se, a cada aluno, a leitura em voz alta do seu próprio texto, procedimento esse que foi gravado em vídeo; imediatamente, os alunos escutaram a gravação e partiram para a reescrita da produção" (MIRANDA, 2015, p. 19). Em seguida, as versões foram comparadas com o objetivo de identificar as operações linguísticas utilizadas pelos estudantes tanto na escrita e reescrita quanto na leitura em voz alta. Destaca-se ainda que cada leitura foi analisada separadamente.

No que diz respeito às operações linguísticas presentes nas reescritas, após a leitura em voz alta do próprio texto, a autora observou as seguintes: a) acréscimo: de grafema, de palavra, de um sintagma, de uma oração, de um parágrafo ou de um texto; b) substituição: de grafema, de palavra, de um sintagma, de uma oração, de um parágrafo ou de um texto; c) supressão: de grafema, de palavra, de um sintagma, de uma oração, de um parágrafo ou de um texto; d) deslocamento: de grafema, de palavra, de um sintagma, de uma oração, de um parágrafo ou de um texto. Desse modo, "os resultados obtidos parecem indicar que o processo de reescrever o próprio texto, com vista ao seu aprimoramento, foi uma preocupação desses estudantes, porque, de uma forma ou de outra, todos modificaram o seu texto" (MIRANDA, 2015, p. 63).

Diante dessas operações linguísticas, pôde-se verificar que "as reformulações apontam para a capacidade de o escritor colocar-se como ouvinte do seu próprio texto e, estando preocupado com o produto a ser apresentado, lançará mão das operações linguísticas necessárias para alcançar esse intento" (MIRANDA, 2015, p. 89). Com isso, conclui-se que a leitura em voz alta é um mecanismo influenciador no processo de revisão e reescrita de textos, uma vez que leva o estudante a perceber as lacunas deixadas na primeira versão do texto, requerendo nas versões seguintes de reescrita empregar adequadamente as operações linguísticas de que o texto precisa para tornar-se significativo tanto para o autor como para o leitor.

Na dissertação intitulada Erros de decodificação no reconhecimento da palavra escrita na leitura em voz alta de alunos do $6^{\circ}$ ano do ensino fundamental, Santos (2016) apresenta uma tipologia de erros de leitura oriunda da leitura em voz alta realizada por estudantes do $6^{\circ}$ ano do ensino fundamental, de uma escola pública municipal de Arapiraca, Alagoas. O texto tem como finalidade analisar os erros tipificados e apresentar um panorama das leituras no que se refere aos comportamentos leitores dos estudantes. Nesse caso, entende-se por comportamentos leitores as intervenções dos estudantes no momento da leitura, como acréscimos, repetições, silabação, entre outros, os quais foram denominados tipos de erros, vindo a constituir a tipologia de erros.

Nesta pesquisa, Santos (2016) avaliou erros de decodificação na leitura de 30 alunos, de uma escola pública municipal da cidade de Arapiraca. Vale mencionar que os 30 participantes não tiveram acesso ao texto antes, ou seja, o texto era apresentado ao aluno no ato da leitura para que uma leitura prévia não interferisse nos dados. Sabe-se que a leitura precedente à 
leitura em voz alta traz benefícios ao leitor e, consequentemente, à leitura mediada pela voz. Após a leitura, Santos (2016) observou que as leituras em voz alta realizadas pelos 30 alunos, de uma turma do $6^{\circ}$ ano do ensino fundamental, demonstraram que estes saíam do $5^{\circ}$ ano do ensino fundamental com leitura insuficiente, ou seja, não havia fluência, tampouco compreensão do texto lido.

Foram encontrados na pesquisa erros como: pausa, leitura silabada, substituição, repetição, decodificação errada de palavra, desrespeito ao sinal gráfico de acentuação, erros complexos, truncamento, erros de leitura de sinais de pontuação, omissões e acréscimos, acréscimos de palavras. Estes erros são, segundo Santos (2016, p. 101), advindos de duas rotas: da rota lexical e da rota não lexical:

Os erros relacionados à rota lexical permitiam o acesso direto ao léxico mental por meio de substituição de palavras, que, apesar de algumas estarem corretas ortograficamente, não faziam sentido dentro do texto. Os erros decorrentes da rota não lexical carecem de uma atenção especial no plano fonológico, já que erros pela rota fonológica implicam uma má ou não compreensão do texto lido. Quando bem administradas pelo professor, essas rotas asseguram uma leitura eficiente, levando o aluno a perceber visualmente a palavra e acioná-la direta e automaticamente em sua memória de trabalho.

Diante disso, o autor (2016) concluiu que a leitura em voz alta pode ser uma aliada à identificação do nível de leitura e compreensão dos alunos, pois, como visto, ainda é comum alunos chegarem ao $6^{\circ}$ ano do ensino fundamental com bastante dificuldades de leitura em termos de decodificação e compreensão leitora.

\section{ConsideraçõEs FinaIS}

Este texto teve como principal finalidade verificar como a leitura em voz alta constitui-se uma prática necessária ao ensino e à aprendizagem em diferentes práticas discursivas nas aulas Língua Portuguesa. Para isso, discorremos sobre textos que versam sobre a prática leitora na sala de aula como constitutiva de sentidos para o desenvolvimento de tantas outras habilidades, como a compreensão de textos, dificuldades na leitura, erros de decodificação, sinalizando a importância da intervenção do professor nesses processos.

Diante disso, foi possível perceber que o trabalho bem direcionado com a leitura em voz alta, na sala de aula, configura-se num relevante instrumento de desenvolvimento de habilidades e competências que tornem os alunos leitores fluentes e competentes, em termos de leitura, compreensão, produção e revisão textual, além de mostrar-se como um sinalizador de que algo precisa ser revisto, demandando urgência no processo de intervenção da leitura. 
Observou-se ainda que, nos documentos oficiais, a leitura em voz alta é uma prática, de algum modo, secundária, já que as menções a ela são muito poucas e que não vislumbra grande importância e contribuição para a formação do leitor. Entende-se, pois, que a leitura em voz alta nesses documentos cumpre somente um papel de prática que pode ser sinalizadora de erros ou como uma motivação para esse tipo de leitura, o que para a leitura em voz alta é escasso. A prática da leitura em voz alta na escola pressupõe inseri-la em contato com outras práticas discursivas como a oralidade, a produção de texto, análise linguística, por exemplo.

Diante do exposto, acreditamos e concordamos com Jean (1997, p. 67) quando diz que “a leitura em voz alta é, então, fonte de diálogo". Não importando se oral ou se escrito, essa prática, se bem compreendida e utilizada, torna-se um recurso necessário e viável à formação do aluno-leitor, do aluno-produtor de textos.

\section{REFERÊNCIAS}

AGOSTINHO, S. Confissões. 2. ed. São Paulo: Penguin Classic Companhia das Letras, 2017.

BRASIL. Parâmetros Curriculares Nacionais: terceiro e quarto ciclos: Língua Portuguesa. Brasília: MECSEF, 1997.

BRASIL. Ministério da Educação. Base Nacional Comum Curricular. Brasília, MEC/CONSED/ UNDIME, 2017.

BRASIL. Ministério da Educação. Secretaria de Alfabetização. PNA Política Nacional de Alfabetização/Secretaria de Alfabetização. Brasília: MEC, SEALF, 2019.

CHARTIER, A.M. Práticas de leitura: história e atualidade. 2. ed. Belo Horizonte: Ceale/ Autêntica Editora, 2011.

CHARTIER, R. Do códice ao monitor: a trajetória do escrito. Estudos avançados, v.8, n.21,1994, p.185-199. Disponível em: https://www.scielo.br/scielo.php?pid=S010340141994000200012\&script=sci_abstract\&tlng=pt. Acesso em: 25 set. 2019.

FISCHER, S. R. História da leitura. São Paulo: Unesp, 2006.

HORELLOU-LAFARGE, C.; SEGRÉ, M. Sociologia da leitura. Cotia: Ateliê Editorial, 2010.

JEAN, G. A leitura em voz alta. Rio de Janeiro: Instituto Piaget, 1997.

LANDIM, M. R. M.; FLÔRES, O. C. Leitura oral: uma variável facilitadora de compreensão. Leitura, Maceió, n. 63, jul./dez., 2019, p. 23-36. Disponível em: https://www.seer.ufal.br/index. $\mathrm{php} /$ revistaleitura/article/view/6978. Acesso em: 15 out. 2020.

MANGUEL, A. Uma história da leitura. São Paulo: Companhia das Letras, 1997. 
MIRANDA, S. C. A influência da leitura em voz alta na revisão de textos de alunos do $9^{\circ}$ ano do ensino fundamental. 2015. 160f. Dissertação (Mestrado Profissional em Letras) - Faculdade de Letras. Universidade Federal de Minas Gerais, Belo Horizonte, 2015.

MORAIS, J. Criar leitores: para professores e educadores. Barueri: Minha Editora, 2013.

OLIVEIRA, M. A. A.; ARAÚJO, A. K. G. Leitura em voz alta e discussões orais: estratégias de ensino nas aulas de Língua Portuguesa. Ensino Em Re-vista, Uberlândia, v.26, n. 3, set./ dez., 2019, p. 763-785. Disponível em: http://www.seer.ufu.br/index.php/emrevista/article/ view/50984. Acesso em: 15 out. 2020.

POERSCH; J. M.: MUNEROLI, A. N. O. O leitor como intérprete das pistas que o escritor insere no texto: a leitura oral expressiva. Letras de Hoje, Porto Alegre, v.28, n. 4, 1993, p. 9-34. Disponível em: https://revistaseletronicas.pucrs.br/ojs/index.php/fale/article/view/16033. Acesso em: 15 out. 2020.

SANTOS, M. S. Erros de decodificação no reconhecimento da palavra escrita na leitura em voz alta de alunos do $6^{\circ}$ ano do ensino fundamental. 2016. 111f. Dissertação (Mestrado Profissional em Letras) - Faculdade de Letras. Universidade Federal de Alagoas, Maceió, 2016.

Recebido para publicação em: 21 abr. 2021. Aceito para publicação em: 6 jul. 2021. 